\title{
Network Supplier Credit Management: Models Based on Petri Net
}

\author{
Yonggui FU, Jianming ZHU
}

\begin{abstract}
In current credit evaluation methods, the credit condition of the network supplier and the credit degree of each index cannot be described well, and the credit evaluation data only source of the transaction platform have much limitation. This research proposes the method of calculating the importance and the value of the credit evaluation indexes, and proposes to put credit evaluation into big data environment. This research uses the transaction process of $\mathrm{B} 2 \mathrm{C}$ as the case, and constructs multiple attribute weighted Petri net credit index subnet (CWPSN) for realizing the credit evaluation of the network supplier, and for presenting the correlations among the evaluation results of the credit evaluation indexes, and for presenting the importance of the indexes and the credit degree of each index, and describes the cost optimization process with credit cost optimization investment process Petri net (CCOIPPN). By the case to verify the credit evaluation method based on Petri net and the cost optimization method based on Petri net. The researches have provided methods for clearly and concretely describing the process of credit evaluation and cost optimization of network supplier, and have guidance significance for similar other researches.
\end{abstract}

Keywords: cost optimization; credit evaluation; network supplier; Petri net

\section{INTRODUCTION}

Credit problems are prominent in the research on ecommerce, especially in the fields of cross-border transactions, coastal transactions, etc. The credit evaluation of the network supplier is key for the customer realizing the transaction, and at present, a large number of related research results have been formed. However, a review shows that current research on credit evaluation mainly focuses on the construction of evaluation index system (such as [1][2]) and evaluation model (such as the classical models that formed basing on the methods of AHP, TOPSIS, principal component analysis, neural network, and SVM, etc., and the integrated models formed by combining these classical models), so the evaluation results cannot effectively embody the credit situation of each section of the transaction process and the correlation relations of the credit evaluation indexes of each section. At the same time, the research usually limits the credit evaluation basis to the data from transaction platform, thus, the accuracy of prior credit evaluation results is limited.

Simulation or modeling can make the relationships or principles of research objects more concise and clear and has been used extensively by researchers, such as [3][4][5]. By constructing computation models to solve economic problems is classical research method in economic field, computation models can explain economic problems more accurately, concretely, and objectively, such as [6][7][8]. In this paper, the authors construct simulation models and computation models to research the credit evaluation problem and cost optimization problem of the network supplier. In 1962, Petri net was first proposed by Dr. Carl A.Petri. Petri net is used to represent the causal relationships among the computer system events [9]. Since it was proposed, Petri net has recieved extensive attention from application fields and academic circles. The typical application fields and research results are shown as the following:

(1) Flexible manufacturing system. Such as Meng and Yan [10] with the help of knowledgeable manufacturing systems' knowledge base, handling and training multi attribute fuzzy Petri net attribute, and regularization processing the irregular model, constructing the subsequent products' multi attribute fuzzy Petri net model on the basis of the original products' multi attribute fuzzy Petri net model. Simon, Oyekan, Hutabarat, et al. [11] constructed the Petri net model for the manufacturing systems.

(2) Work process and characteristics analysis. Such as $\mathrm{Li}$, Wang, and Qiao [12] based on the isomorphism relations of generalized stochastic Petri net and Markov chain, constructing serious infectious disease propagation evolution's generalized Petri net model and the corresponding Markov chain model. Han, Yuan, and Ye [13] combined random Petri net and triangular fuzzy parameters to realize the interrelationship determination for products' multi craftwork production and working procedure production cycle's fluctuations. Chen, Huang, and Chu [14] used dynamic fuzzy Petri net to improve the flexibility of teaching methods, and provided the structure of electronic teaching content for the learners.

(3) Supply chain management. Zhang,You, Jiao, et al. [15] used the colored Petri net model to construct and analyze supply chain, and used case to explain. Wang and $\mathrm{Da}$ [16] based on the isomorphism relations of generalized stochastic Petri net and Markov chain, and with the help of Markov chain and the related model methods to analyze the remanufacturing supply chain's time, transition utilization ratio, operation efficiency etc. performance indexes.

(4) Electronic commerce and transaction. Gan, Wang, Wei, and Zhang [17] used Petri net to construct electronic commerce environment's tax business process model, and used matrix equations to do the analysis and validation for the model.

In addition, Petri net has also achieved extensive researches and applications in the fields of project management (such as [18]), system failure analysis (such as [19][20]), simulation control (such as [21][22][23]), etc.

Colligating the characteristics of Petri net, and Petri net models' application research results from different fields in recent years, the main advantages of Petri net can be shown as the following:

(1) Petri net model is systematic, and can be effectively used to describe the correlations among system events.

(2) Petri net model can be used to describe the concurrent, asynchronous, etc. characteristics of complex 
system from the point of view of process.

(3) Petri net model is suitable for the modeling of workflows or business flows, and contains the trigger conditions of events.

(4) The things described by Petri net model own the characteristic of temporality.

(5) Petri net model contains large amount of information, complex structure, and is suitable for dynamic expansion.

Basing on the characteristics of Petri net, for each section of the whole transaction for the supplier, the researchers can with Petri net effectively analyze the level of the credit evaluation indexes for the supplier and the correlations among the indexes. At the same time, Petri net model also has a very good describing ability for the network supplier cost optimization investment analysis and implementation process on credit evaluation index. Therefore, it is significance for Petri net model applying in network supplier's credit evaluation and credit evaluation indexes' cost investment optimization process. With the development and application of information technology, mankind has already entered into big data era. Big data have the characteristics as multisource of information, greatness of information amount, and comprehensiveness of information content. Compared with local data, through mining to the information contained in big data, the researchers can get more comprehensive and concrete information structure and content. Based on big data analysis, the decision will be more accurate and reliable.

By expanding the sources and amount of data, the researchers can eliminate the sidedness and instability of local data reflecting to things, making the reflection of data analysis to things more close to the true features of things, so, it also has practical significance for big data technology applied in network supplier credit evaluation.

Nevertheless, through colligating the existing research results, the authors haven't found any results that used Petri net model to analyze the credit evaluation index structure of the network supplier of each section for the whole transaction process, the correlations for the evaluation results of the credit evaluation indexes, the emphasis of the customers to the credit degree of the credit evaluation indexes, and the evaluation results of the credit evaluation indexes. The authors also haven't found any results that used the related big data to evaluate the credit degree of network supplier. At present, the research on supplier credit cost investment optimization is less, and the authors haven't found the research results on using Petri net model to describe and analyze the supplier credit evaluation index cost investment optimization process.

So, in this paper, the authors propose inducing the supplier's credit evaluation related big data outside the transaction platform, together with the supplier's credit evaluation related data in the transaction platform as the supplier's credit evaluation data set, and construct the multi attribute weighted Petri net credit index subnet for the transaction process of the supplier, for analyzing and describing the supplier's credit evaluation indexes and the correlations of the evaluation results of the indexes more effectively and fully. Aiming at the analysis results of multi attribute weighted Petri net credit index subnet to further construct supplier credit evaluation index cost investment optimization process Petri net model, providing measures and guidance for supplier optimizing cost investment for improving its credit degree. Obviously, this paper research has very strong novelty and foresight.

\section{NETWORK TRANSACTION PROCESS AND CREDIT EVALUATION DATA SOURCE OF THE SUPPLIER}

Classified by transaction architecture mode, the network transaction can be divided into different modes as: B2C, B2B, C2C, O2O, E-shop, etc. Compared with other transaction modes, B2C embodies a wider transaction range, and a higher transaction frequency, while the transaction stability and cognition degree between the supplier and the customer is poorer. Therefore, the problems on the supplier credit evaluation of $\mathrm{B} 2 \mathrm{C}$ are more extensive and necessary. So, this paper makes the supplier credit evaluation of $\mathrm{B} 2 \mathrm{C}$ the object to research, and the research results will have the same guidance significance and application value to the supplier credit evaluation of the other transaction modes.

Due to the characteristics of different B2C platforms are different, the transaction process of different $\mathrm{B} 2 \mathrm{C}$ platforms also have some differences. So, after researching and analyzing multiple classical B2C platforms, the authors proposed the normal structure of $\mathrm{B} 2 \mathrm{C}$ transaction process as seen Fig. 1. It needs to be explained, the research in this paper has the characteristics of universality, and the research thoughts and methods are independent to the transaction process.

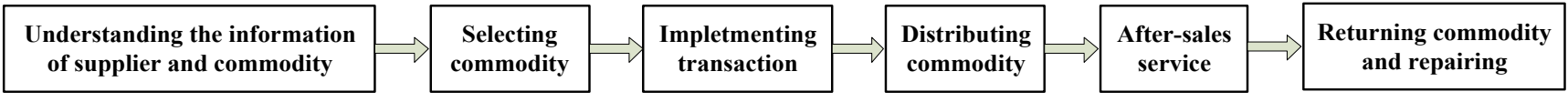

Figure 1 The transaction process of $\mathrm{B} 2 \mathrm{C}$

In Fig. 1, the business activities as understanding the information of supplier and commodity, selecting commodities, are implemented by the customers, and the business activities as distributing commodities, providing after-sales service, returning and repairing commodities are implemented by the network supplier. Each section of B2C transaction contains several indexes for evaluating credit of the network supplier, and all these indexes compose the index system for evaluating credit of the network supplier.

The data sources of credit evaluation indexes for network supplier root in network, and all the transaction information are stored in the transaction platform. Because the reflection is inadequate for transaction platform's information to credit condition of the supplier, therefore, in order to reflect credit degree of the supplier more exactly and precisely, the authors propose to synthetically analyze the data set or information that root in the supplier's website, transaction platform, and all the other related data sources as well as the forums on the credit evaluation for the customers to the supplier. If the supplier's influence is large enough, and its historical transaction time is long 
enough, in network, the data sources of the supplier's businesses (such as production, operation, etc.) will be numerous enough, and the data amount will also be great enough. So, the network supplier credit evaluation related data sources' data capacity will run up to capacity level of big data. Therefore, by analyzing the network supplier credit evaluation related big data, the researchers can achieve the supplier credit more precisely and objectively.

In the big data environment, the data source structure of credit evaluation data for $\mathrm{B} 2 \mathrm{C}$ transaction providers is shown in Fig. 2.

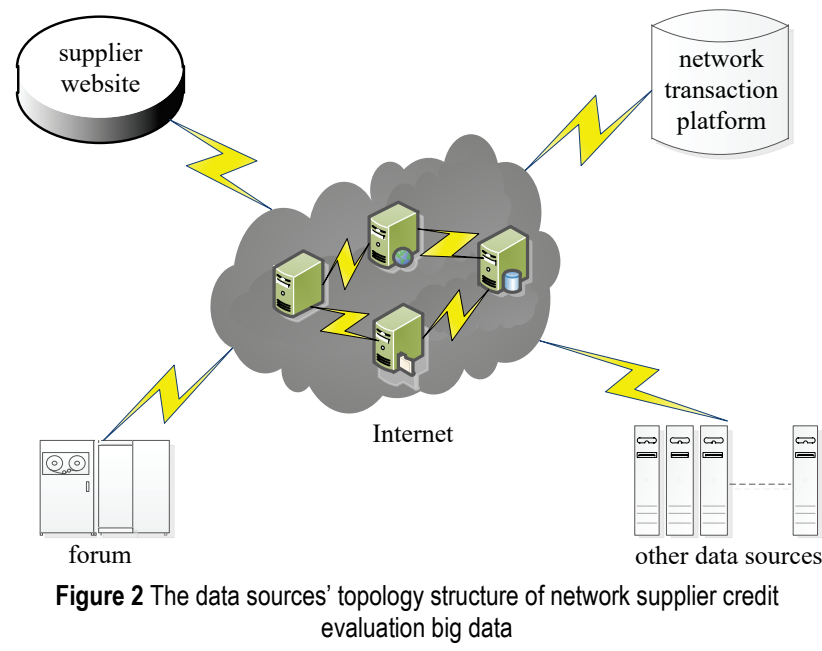

Fig. 2 illustrates the topology structure of the data sources. The sources of B2C network supplier data were extended to the whole Internet. When the data of data sources in Internet cannot satisfy network supplier credit evaluation requirement, the researchers can consider using data sources outside the Internet, such as Intranet used by the network supplier or non-network data sources. Due to data sources of network supplier credit evaluation are different, so in general the difference of the data structure is also big, therefore, in the process of credit evaluation the researchers need to consider the problems of data cleaning and data format standardization. Because these problems are not very relevant to this paper's research topic, so the authors will no longer discuss these issues.

\section{CREDIT EVALUATION OF THE NETWORK SUPPLIER BASED ON PETRI NET}

This paper intends to use the Petri net model to analyze the credit degree of the network supplier for B2C, because in each transaction section, usually, several indexes are used for the supplier credit evaluation, and the Petri net models are constructed based on the transaction process of $\mathrm{B} 2 \mathrm{C}$, therefore, in this paper, each place of the Petri net also accordingly contains the indexes for the supplier credit evaluation. Each place contains several indexes for credit evaluation, and the credit evaluation indexes contained in different place are also different separately, so, the Petri net model constructed in this paper is multi attribute credit evaluation index Petri net. Because each index varies in its contribution to the credit evaluation of the supplier, thus, the authors assign a weight to each index in Petri net, so, the Petri net constructed in this paper is a weighted Petri net, specifically, the Petri net is a multi-attribute weighted
Petri net credit index subnet, abbreviated as CWPSN. For the customers, the importance of different credit evaluation index is also different, so, in the model of CWPSN, it is not only the credit evaluation index value need be reflected, but also the importance of the index need be reflected. If the researchers induced time factor to CWPSN, the Petri net will be a generalized stochastic Petri net [9][16], because the research content in this paper does not refer to the concrete analysis methods used for a generalized stochastic Petri net, so, the authors will not any more minutely discuss its related properties.

For multi attribute Petri net, the research results can be seen such as [10], its ideas and theories are consistent with colored Petri net [9][24]. Colored Petri net is classified by the signs of Petri net, using different colors to mark different classifications of signs, and in the whole Petri net the color classifications of each place are fixed. Currently, there are many research results for colored Petri net, such as [25][26]. For the multi attribute Petri net proposed in this paper, each place contains several credit evaluation indexes, and the credit evaluation indexes contained in different place are also different, so the authors haven't used colored Petri net to define the Petri net proposed in this paper.

\subsection{Importance Calculation for the Credit Evaluation Index}

By analyzing big data on the credit evaluation of the supplier used for B2C transaction, for a certain period of time, the emphasis and evaluation attitude of the customers to credit evaluation indexes contained in each place in CWPSN can be obtained. Synthetically, for this period of time, the overall credit evaluation results of the supplier can be obtained.

For a certain period of time, the emphasis of the customers to some a credit evaluation index of the supplier, reflects the importance of the index for the customers evaluating the credit of the supplier. This paper makes the evaluation frequency $t f_{k}$ of the customers to some an index ( $k$ represents the $k^{\text {th }}$ credit evaluation index), as the importance's determination foundation of the index for the customers evaluating the credit of the supplier, and makes the evaluation frequency of the customers to some an index be divided by the maximum evaluation frequency of customers to all indexes, as the importance $I M_{k}$ of the index to the customers, so, $I M_{k}=t f_{k} / \max _{k}\left\{t f_{k}\right\}$.

\subsection{Evaluation Result Calculation for the Credit Evaluation Index}

Through analyzing big data on credit for the network supplier transacting, the researchers can separately obtain the frequency of different evaluation results of some index. Computing the relative value of the frequency of the different evaluation results and assigning it weight, as the ultimate evaluation result of the customers to the index. To different index, the data sources of the corresponding credit related big data will also be different, the data sources can be the website of the supplier, the transaction of the supplier, and sources of data on the other network behaviors of the supplier, in addition, the credit related data are stored by other institutions, etc. To some an index, in the big data environment, the authors classify the 
evaluation results from the customers as "high", "medium", and "low" three classifications, the relative value of the evaluation frequency for "high", "medium", and "low" three classifications are $f_{k}{ }^{H}=t f_{k}^{H} / t f_{k}, f_{k}^{M}=t f_{k}{ }^{M} / t f_{k}$, $f_{k}{ }^{L}=t f_{k}^{L} / t f_{k}$. (Where, $t f_{k}^{H}, t f_{k}^{M}$, and $t f_{k}^{L}$ represent the relative value of the evaluation frequency of the $k^{\text {th }}$ index) So, the evaluation result of the index can be calculated as: $m_{k}=\delta_{1} \times f_{k}^{H}+\delta_{2} \times f_{k}^{M}+\delta_{3} \times f_{k}^{L}, 0 \leq \delta_{1}, \delta_{2}, \delta_{3} \leq 1$.

Through analyzing the importance and the value of the credit evaluation index of the supplier, the researchers can ascertain the most concerned indexes for the customers and the indexes with lower credit value.

\subsection{The Definition of CWPSN}

On the basis of the above analysis, the authors define CWPSN with an eleven tuple.

Definition $1 C W P S N=(P, T, F, D, I, O, V, M, W, \alpha, \lambda)$, it's implication is as following:

(1) $P=\left\{p_{1}, p_{2}, \ldots, p_{n}\right\}$, and it denotes a finite set of places.

(2) $T=\left\{t_{1}, t_{2}, \ldots, t_{s}\right\}$, and it denotes a finite set of transitions, and $P \cap T=\phi$.

(3) $F$, and it denotes a set of connections, and denotes the data flow relations between the places and transitions.

(4) $D=\left\{d_{1}, d_{2}, \ldots, d_{n}\right\}$, and it denotes a finite set of definitions, thereof, $d_{i}=\left\{d_{i}{ }^{1}, d_{i}{ }^{2}, \ldots, d_{i}^{t}\right\},(1 \leq i \leq n)$.

(5) $I: P \times T \rightarrow\{0,1\}$, and it denotes input function, and denotes $p$ is related to $t$.

(6) $O: T \times P \rightarrow\{0,1\}$, and it denotes output function, and denotes $t$ is related to $p$.

(7) $V=\left\{v\left(p_{1}\right), v\left(p_{2}\right), \ldots, v\left(p_{n}\right)\right\}$, and it denotes the importance set for each place contained credit evaluation indexes to the customers. Thereof, $v\left(p_{i}\right)=$ $\left\{v\left(p_{i}\right)^{1}, v\left(p_{i}\right)^{2}, \ldots, v\left(p_{i}\right)^{t}\right\},(1 \leq i \leq n), \quad$ denotes the importance set for the ith place contained credit evaluation indexes to the customers (Here, in $V=$ $\left\{v\left(p_{1}\right), v\left(p_{2}\right), \ldots, v\left(p_{n}\right)\right\}$, the $k^{\text {th }}$ credit evaluation index's importance value to the customers, is corresponding to the $k^{\text {th }}$ credit evaluation index's importance value computing result $I M_{k}$ in section "Importance Calculation for the Credit Evaluation Index").

(8) $M=\left\{m\left(p_{1}\right), m\left(p_{2}\right), \ldots, m\left(p_{n}\right)\right\}$, and it denotes the value set of each place contained credit evaluation index (i.e., the expression of each place contained credit evaluation index set to the credit degree of network supplier), thereof, $m\left(p_{i}\right)=\left\{m\left(p_{i}\right)^{1}, m\left(p_{i}\right)^{2}, \ldots, m\left(p_{i}\right)^{t}\right\}$, $(1 \leq i \leq n)$ denotes the value set of the $i$ th place contained credit evaluation index (Here, in $M=$ $\left\{m\left(p_{1}\right), m\left(p_{2}\right), \ldots, m\left(p_{n}\right)\right\}$, the $k^{\text {th }}$ index's credit evaluation value is corresponding to the $k^{\text {th }}$ index's credit evaluation value $m_{k}$ in section "Evaluation Result Calculation for the Credit Evaluation Index").

(9) $W=\left\{w\left(p_{1}\right), w\left(p_{2}\right), \ldots, w\left(p_{n}\right)\right\}$, and it denotes the weight set of each place contained credit evaluation index, $w\left(p_{i}\right)=\left\{w\left(p_{i}\right)^{1}, w\left(p_{i}\right)^{2}, \ldots, w\left(p_{i}\right)^{t}\right\},(1 \leq i \leq n)$ denotes the weight set of the $i^{\text {th }}$ place contained credit evaluation index, thereof, $\sum_{j=1}^{t} w\left(p_{i}\right)^{j}=w\left(p_{i}\right)$, and $\sum_{i=1}^{n} w\left(p_{i}\right)=1$.

(10) $\alpha: P \rightarrow[0,1]$, and it denotes $P$ 's correlation function, and denotes the data mapping relations of $P$ 's credit evaluation indexes to region $[0,1]$.

(11) $\lambda=\left\{\lambda_{1}, \lambda_{2}, \ldots, \lambda_{s}\right\}, \lambda_{i} \in[0,1],(1 \leq i \leq s)$, and it denotes the threshold value of transition $T$, and denotes the transition trigger restriction of the credit value that obtained by synthetically computing $m\left(p_{i}\right)$ contained credit evaluation result of each index.

The structure of CWPSN is shown in Fig. 3.

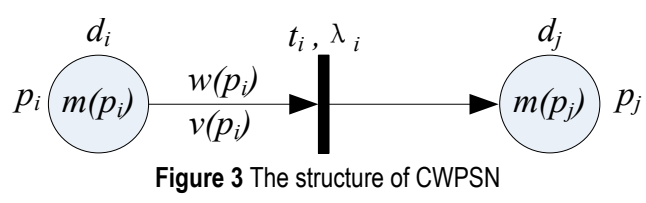

\section{OPTIMIZATION FOR CREDIT COST INVESTMENT OF THE SUPPLIER}

\subsection{Cost Optimization Method}

With big data technology the researchers can obtain the importance of each credit evaluation index to the customers, and the evaluation result of each credit evaluation index, and can obtain the credit evaluation correlations between different credit evaluation indexes. For maintaining its good credit image in the network, in CWPSN, to the lower credit degree indexes and the indexes belonging transaction process sections, with the supplier network transaction related big data the supplier would analyze its cost investment situations in these sections and the sections contained indexes, by analyzing the indexes' credit investment's marginal cost and marginal profit, as the basis of the supplier investing in the corresponding sections and the sections contained indexes. For the bigger difference indexes of the comparison of marginal cost and marginal profit, the supplier will optimize the cost investment according to the ascending order of the ratio of marginal cost and marginal profit, for the indexes which evaluation results are well correlated, in the process of optimizing cost investment, the supplier need consider the correlation, and corresponding to invest in proportion.

Marked credit evaluation index with $q$, so, the formalization description can be shown as follows:

(1) Forth index $q$, if $M C(q)<M R(q)$ and its credit evaluation value is less than a threshold $\beta$, the supplier will consider the index credit investment's cost optimization (because the supplier cannot control credit evaluation indexes that exist in the external economic surroundings, we do not consider the indexes' cost optimization problem), and according to the descending order of $\operatorname{MR}(q) / M C(q)$ to optimize the indexes' investment cost, in the end make each index's credit evaluation value greater than the threshold $\beta$ or reach to a maximum feasible value that is less than $\beta$ (except for some indexes that cannot be optimized).

(2) In the process of cost optimization, it need consider the correlations among the indexes' credit evaluation results, for some indexes which credit evaluation value are less than threshold $\beta$ and have high 
correlations, it need optimize according the same proportion, to avoid the waste of investment cost.

\subsection{Cost Optimization Investment Process Petri Net Model}

The process for network supplier credit cost investment can also be described by Petri net model, in here it is called Credit Cost Optimization Investment Process Petri Net, abbreviated as CCOIPPN. Obviously, the output of the CWPSN is the input of the CCOIPPN.

Because CCOIPPN and CWPSN all are constructed based on $\mathrm{B} 2 \mathrm{C}$ transaction process, so the structure and definition between CCOIPPN and CWPSN has a high degree of similarity, but because CCOIPPN is constructed for supplier credit cost optimization investment process, so, in CCOIPPN, the correlations between different credit indexes should be marked.

Basing on the above analysis, the authors define $C C O I P P N$ with a fifteen tuple.

Definition $2 C C O I P P N=(P P, T T, F F, D D, I I, O O$, $\left.M M, M R C, \alpha \alpha, \beta, R R, U U, P P^{*}, T T^{*}, D D^{*}\right)$, its implication is:

(1) $P P=\left\{p p_{1}, p p_{2}, \ldots, p p_{n}\right\}$, and it denotes a finite set of places. Unlike $C W P S N$, in here, each place contains only one credit evaluation index.

(2) $T T=\left\{t t_{1}, t t_{2}, \ldots, t t_{s}\right\}$, and it denotes a finite set of transitions, and $P P \cap T T=\varphi$.

(3) $F F$, and it denotes a set of connections, and denotes the data flow relations between the places and transitions.

(4) $D D=\left\{d d_{1}, d d_{2}, \ldots, d d_{n}\right\}$, and it denotes a finite set of definitions, thereof, $(1 \leq i \leq n)$.

(5) $I I: P P \times T T \rightarrow\{0,1\}$, and it denotes input function, and denotes $p p$ is related to $t$.

(6) $O O: T T \times P P \rightarrow\{0,1\}$, and it denotes output function, and denotes $t t$ is related to $p p$.

(7) $M M=\left\{m\left(p p_{1}\right), m\left(p p_{2}\right), \ldots, m\left(p p_{n}\right)\right\}$, and it denotes each place contained credit evaluation index value.

(8) $M R C=\left\{\operatorname{mrc}\left(p p_{1}\right), \operatorname{mrc}\left(p p_{2}\right), \ldots, \operatorname{mrc}\left(p p_{n}\right)\right\}$, and it denotes the ratio $M R(q) / M C(q)$ of marginal profit and marginal cost of credit evaluation index contained in each place.

(9) $\alpha \alpha: P P \rightarrow[0,1]$, and it denotes $P P$ 's correlation function, and denotes the data mapping relations of $P P$ 's credit evaluation index to region $[0,1]$, so, $\alpha \alpha\left(p p_{i}\right) \in[0,1]$.

(10) $\beta=\left\{\beta_{1}, \beta_{2}, \ldots, \beta_{s}\right\}, \beta_{i} \in[0,1],(1 \leq i \leq s)$, and itdenotes the threshold value of transition $T T$, and denotes the credit cost optimization investment's transition trigger restriction, and the transition trigger condition is each place contained index's credit evaluation value $m\left(p p_{i}\right)$ less than the corresponding threshold.

(11) $R R=\left\{r r_{1}, r r_{2}, \ldots, r r_{w}\right\}$, and it denotes the correlation transitions of the places, in each place respectively contains a credit evaluation index and the indexes have correlations.

(12) UU, and it denotes a set of correlation connections, and denotes different places contained indexes' credit evaluation results are correlated.

(13) $P P^{*}=\left\{p p_{1}{ }^{*}, p p_{2}{ }^{*}, \ldots, p p_{x}{ }^{*}\right\}$, and it denotes a finite set of places, in each place contains a credit evaluation index to optimize cost investment.

(14) $T T^{*}=\left\{t t_{1}{ }^{*}, t t_{2}{ }^{*}, \ldots, t t_{y}{ }^{*}\right\}$, and it denotes a finite set of transitions, and denotes the cost optimization for the credit evaluation index contained in the corresponding place, and $P P^{*} \cap T T^{*}=\varphi$.

(15) $G G^{*}=\left\{d d_{1}{ }^{*}, d d_{2}{ }^{*}, \ldots, d d_{x}^{*}\right\}$, and it denotes a finite set of definitions, thereof, $(1 \leq i \leq x)$.

In addition, for simplifying CCOIPPN's structure, the authors have not marked the relevance and the corresponding connections of $p p^{*}$ and $t t^{*}$, the transition trigger condition of $t t^{*}$ is cost optimization process over, the authors also haven't marked, etc.

The structure of CCOIPPN can be shown in Fig. 4 (in Fig. 4, "०" denotes conditional choice sign, the virtual arrow and the corresponding transition refer to the credit evaluation indexes contained in the two places have credit correlation. $p p_{j} \rightarrow t t_{j} \rightarrow p p_{j}{ }^{*} \rightarrow t t_{j}{ }^{*} \rightarrow p p_{j}$ denotes the cost optimization investment process of credit evaluation index $p p_{j}$. Here, in Fig. 4 the authors need to explain, the different indexes only according to the descending order of $\operatorname{mrc}\left(p p_{i}\right)$ $(1 \leq i \leq n)$ to optimize the cost investment, while not according to the order of $\mathrm{B} 2 \mathrm{C}$ transaction process. That is, any $t t^{*}$ lags all $t t$ in sequence. In Fig. 4, the authors mark credit evaluation indexes' cost optimization investment process only for explaining the characteristics of different credit evaluation indexes' cost optimization investment business structure.)

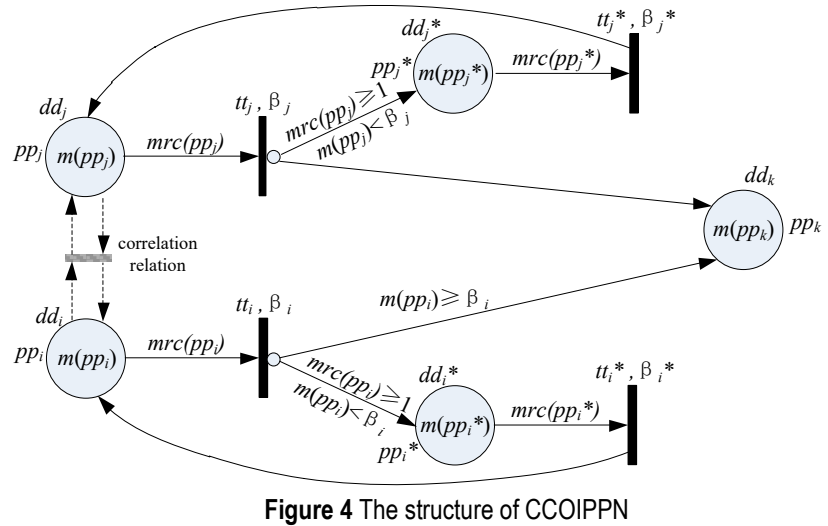

\section{CASE ANALYSIS}

In order to distinguish the place $p_{i}$ of $C W P S N$ and $p p_{i}$ of CCOIPPN, in here, the credit evaluation index is marked with $q_{i}^{j}$, at the same time considering the consistency with CWPSN's definition, the credit evaluation value of $q_{i}^{j}$ is still marked with $m\left(p_{i}\right)^{j}$, and the weight is still marked with $m\left(p_{i}\right)^{j}$, the relations among $p_{i}, p p_{i}$, and $q_{i}{ }^{j}$, and their definitions are shown in Tab. 1, Tab. 3 and Tab. 5.

\subsection{Credit Evaluation Process Analysis}

Uniting the framework characteristics of Fig. 1, this paper assumes the CWPSN model for $\mathrm{B} 2 \mathrm{C}$ transaction process can be shown in figure 5, in figure 5, the authors do not mark the value of $w\left(p_{i}\right)^{j}$. For researching easily, the authors assume $\lambda_{i}=0.4,(1 \leq i \leq s)$, which means that if the credit evaluation value of the index contained in a place is less than 0.4 , then the transition will not be triggered, the transition will be broken off, and the network supplier will lose all its customers (this assumption only is a theoretical assumption, and although this assumption has 
not reflected the actual situation, but its research thoughts are practicable). For simplicity, this paper does not mark $\lambda_{i}$ in Fig. 5. Here, for producing the value of $w\left(p_{i}\right)$ and $w\left(p_{i}\right)^{j}$, the authors have acquired the evaluation results from some experts through applying fuzzy comprehensive evaluation method.

In this case, the related big data of credit evaluation of the network supplier are limited to current a certain time range (the time range can be a week, or a month, etc.).

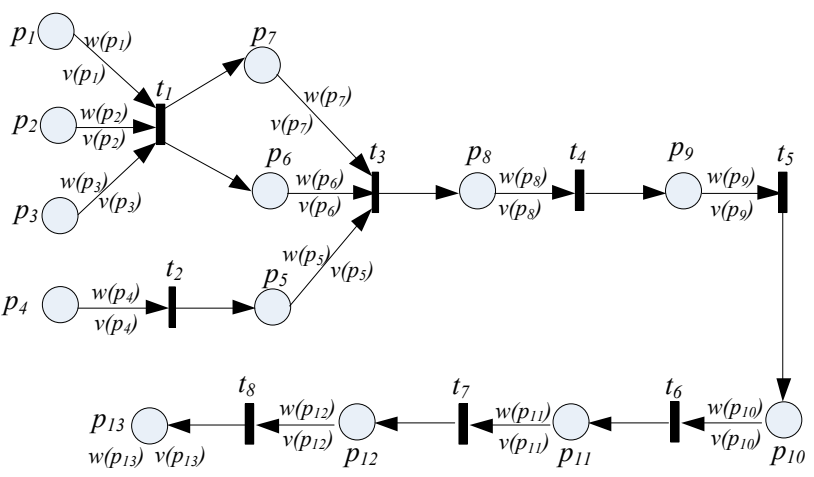

Figure 5 B2C transaction process' CWPSN model

Each place's implication can be seen in Tab. 1.

In the research process, the authors organized 25 experts, and the experts are e-commerce major teachers from universities, the entrepreneurs who good at ecommerce technology, experts for enterprise credit evaluation, etc., by the experts marking the weight of related each grade indexes. After synthesizing, the authors give the indexes contained in each place and the weight of the indexes, all can be seen in Tab. 3 .
Table 1 Each place's implication in CWPSN model Implications

\begin{tabular}{|c|l|}
\hline Place & \multicolumn{1}{|c|}{ Implications } \\
\hline$p_{1}$ & The external economic surroundings for the supplier \\
\hline$p_{2}$ & The economic quality and future development for the supplier \\
\hline$p_{3}$ & The historical transaction credit evaluation for the supplier \\
\hline$p_{4}$ & The whole credit degree of the commodities \\
\hline$p_{5}$ & The credit degree for pre purchase commodity \\
\hline$p_{6}$ & The credit degree for order acceptance \\
\hline$p_{7}$ & The credit degree for payment \\
\hline$p_{8}$ & The credit degree for commodity distribution \\
\hline$p_{9}$ & The credit degree for after-sales service acceptance \\
\hline$p_{10}$ & The credit degree for after-sales service \\
\hline$p_{11}$ & The credit degree for accepting to return and repair commodity \\
\hline$p_{12}$ & The credit degree for returning and repairing commodity \\
\hline$p_{13}$ & $\begin{array}{l}\text { The credit degree for the durability and constancy of the use of } \\
\text { the commodity }\end{array}$ \\
\hline
\end{tabular}

Each transition's implication can be seen in Tab. 2.

\begin{tabular}{|c|l|}
\multicolumn{2}{c}{ Table 2 Each transition's implication in CWPSN model } \\
\hline Transition & \multicolumn{1}{c|}{ implications } \\
\hline$t_{1}$ & $\begin{array}{l}\text { Analysis on the credit degree of the indexes of the } \\
\text { internal and external economic surroundings for the } \\
\text { supplier and the credit degree of the historical transaction } \\
\text { for the supplier }\end{array}$ \\
\hline$t_{2}$ & Analysis on the overall credit degree of the commodities \\
\hline$t_{3}$ & Transaction implementation \\
\hline$t_{4}$ & Commodity distribution \\
\hline$t_{5}$ & Acceptance after-sales service \\
\hline$t_{6}$ & After-sales service \\
\hline$t_{7}$ & Accept to return and repair the commodity \\
\hline$t_{8}$ & Return and repair the commodity \\
\hline
\end{tabular}

Set $\delta_{1}=1, \delta_{2}=0.7, \delta_{3}=0.4$. Through big data analysis, the authors obtained the importance value and the credit value of each credit evaluation index for a network supplier, all can be seen in Tab. 4.

Table 3 The supplier credit evaluation each place contained indexes $\left(q_{i}^{j}\right)$ and the indexes' weight value $\left(w\left(p_{i}\right)^{j}\right)$

\begin{tabular}{|c|c|c|c|c|}
\hline \multirow{2}{*}{ Place } & \multicolumn{2}{|c|}{ Index } & \multicolumn{2}{|c|}{ Weight } \\
\hline & First-grade index & Second-grade index & Identification & Value \\
\hline \multirow[b]{2}{*}{$p_{1}$} & \multirow{2}{*}{ The external economic surroundings for the supplier $\left(q_{1}\right)$} & The supply and demand condition for industry $\left(q_{1}^{1}\right)$ & $w\left(p_{1}\right)^{1}$ & 0.02 \\
\hline & & The overall economic surroundings for nation $\left(q_{1}^{2}\right)$ & $w\left(p_{1}\right)^{2}$ & 0.01 \\
\hline \multirow{3}{*}{$p_{2}$} & \multirow{3}{*}{$\begin{array}{l}\text { The economic quality and future development for the } \\
\text { supplier }\left(q_{2}\right)\end{array}$} & The overall quality for the supplier $\left(q_{2}^{1}\right)$ & $w\left(p_{2}\right)^{1}$ & 0.02 \\
\hline & & The assets' and liabilities' condition for the supplier $\left(q_{2}^{2}\right)$ & $w\left(p_{2}\right)^{2}$ & 0.06 \\
\hline & & The future development for the supplier $\left(q_{2}^{3}\right)$ & $w\left(p_{2}\right)^{3}$ & 0.02 \\
\hline$p_{3}$ & \multicolumn{2}{|c|}{ The credit evaluation value for historical transaction $\left(q_{3}\right)$} & $w\left(p_{3}\right)$ & 0.30 \\
\hline$p_{4}$ & \multicolumn{2}{|l|}{ The whole credit degree value for the commodities $\left(q_{4}\right)$} & $w\left(p_{4}\right)$ & 0.10 \\
\hline$p_{5}$ & \multicolumn{2}{|l|}{ The credit degree value for pre-purchase commodity $\left(q_{5}\right)$} & $w\left(p_{5}\right)$ & 0.20 \\
\hline$p_{6}$ & \multicolumn{2}{|l|}{ The credit degree value for order acceptance $\left(q_{6}\right)$} & $w\left(p_{6}\right)$ & 0.03 \\
\hline \multirow[b]{2}{*}{$p_{7}$} & \multirow{2}{*}{ The credit degree value for payment } & The convenience degree value for payment $\left(q_{7}{ }^{1}\right)$ & $w\left(p_{7}\right)^{1}$ & 0.03 \\
\hline & & The security performance value for payment $\left(q_{7}^{2}\right)$ & $w\left(p_{7}\right)^{2}$ & 0.02 \\
\hline \multirow[b]{2}{*}{$p_{8}$} & \multirow{2}{*}{ The credit degree value for commodity distribution } & The distribution period for commodity $\left(q_{8}{ }^{1}\right)$ & $w\left(p_{8}\right)^{1}$ & 0.02 \\
\hline & & The distribution credit value for commodity $\left(q_{8}^{2}\right)$ & $w\left(p_{8}\right)^{2}$ & 0.05 \\
\hline$p_{9}$ & \multicolumn{2}{|l|}{ The credit degree value for after-sales service acceptance $\left(q_{9}\right)$} & $w\left(p_{9}\right)$ & 0.01 \\
\hline$p_{10}$ & \multicolumn{2}{|l|}{ The credit degree value for after-sales service $\left(q_{10}\right)$} & $w\left(p_{10}\right)$ & 0.02 \\
\hline$p_{11}$ & \multicolumn{2}{|c|}{ The credit degree value for accepting to return and repair commodity $\left(q_{11}\right)$} & $w\left(p_{11}\right)$ & 0.02 \\
\hline$p_{12}$ & \multicolumn{2}{|c|}{ The credit degree value for returning and repairing commodity $\left(q_{12}\right)$} & $w\left(p_{12}\right)$ & 0.02 \\
\hline$p_{13}$ & \multicolumn{2}{|c|}{ The credit degree value for the durability and constancy of commodity using $\left(q_{13}\right)$} & $w\left(p_{13}\right)$ & 0.05 \\
\hline
\end{tabular}

Table 4 The importance $\left(v\left(p_{i}\right)^{j}\right)$ and credit value $\left(m\left(p_{i}\right)^{j}\right)$ of each index $\left(q_{i}^{j}\right)$

\begin{tabular}{|c|c|c|c|c|c|c|c|c|c|c|c|}
\hline Index & $v\left(p_{i}\right)^{j}$ & $m\left(p_{i}\right)^{j}$ & $f^{L}$ & $f^{M}$ & $f^{H}$ & Index & $v\left(p_{i}\right)^{j}$ & $m\left(p_{i}\right)^{j}$ & $f^{L}$ & $f^{M}$ & $f^{H}$ \\
\hline$q_{1}{ }^{1}$ & 0.23 & 0.87 & 0.00 & 0.45 & 0.55 & $q_{7}^{1}$ & 0.57 & 0.96 & 0.01 & 0.11 & 0.88 \\
\hline$q_{1}^{2}$ & 0.19 & 0.85 & 0.12 & 0.25 & 0.63 & $q_{7}^{2}$ & 0.61 & 1.00 & 0.00 & 0.00 & 1.00 \\
\hline$q_{2}{ }^{1}$ & 0.45 & 0.93 & 0.03 & 0.16 & 0.81 & $q_{8}{ }^{1}$ & 0.85 & 0.95 & 0.00 & 0.17 & 0.83 \\
\hline$q_{2}^{2}$ & 0.62 & 0.93 & 0.04 & 0.14 & 0.82 & $q_{8}^{2}$ & 0.83 & 1.00 & 0.00 & 0.01 & 0.99 \\
\hline$q_{2}{ }^{3}$ & 0.33 & 0.92 & 0.05 & 0.16 & 0.79 & $q_{9}$ & 0.58 & 0.96 & 0.00 & 0.12 & 0.88 \\
\hline$q_{3}$ & 1.00 & 0.95 & 0.04 & 0.08 & 0.88 & $q_{10}$ & 0.53 & 0.97 & 0.00 & 0.11 & 0.89 \\
\hline$q_{4}$ & 0.63 & 0.87 & 0.00 & 0.44 & 0.56 & $q_{11}$ & 0.49 & 0.76 & 0.02 & 0.75 & 0.23 \\
\hline$q_{5}$ & 0.66 & 0.87 & 0.00 & 0.45 & 0.55 & $q_{12}$ & 0.46 & 0.76 & 0.01 & 0.77 & 0.22 \\
\hline$q_{6}$ & 0.39 & 1.00 & 0.00 & 0.01 & 0.99 & $q_{13}$ & 0.88 & 0.90 & 0.04 & 0.24 & 0.72 \\
\hline
\end{tabular}


Uniting Tab. 3 and Tab. 4, the total credit value of the supplier is calculated as $M=\sum m\left(p_{i}\right)^{j} \times w\left(p_{i}\right)^{j}=0.92$, through analyzing Tab. 4 the researchers can know, the emphasis of the customers to the indexes in descending order as: $q_{3}, q_{13}, q_{8}{ }^{1}, q_{8}{ }^{2}, q_{5}, q_{4}, q_{2}^{2}, q_{7^{2}}, q_{9}, q_{7}{ }^{1}, q_{10}, q_{11}, q_{12}$, $q_{2}{ }^{1}, q_{6}, q_{2}{ }^{3}, q_{1}{ }^{1}, q_{1}{ }^{2}$. The credit evaluation value of each index for the supplier in descending order as: $q_{6}, q_{7}{ }^{2}, q_{8}^{2}$, $q_{10}, q_{7}{ }^{1}, q_{9}, q_{3}, q_{8}{ }^{1}, q_{2}{ }^{1}, q_{2}{ }^{2}, q_{2}{ }^{3}, q_{13}, q_{1}{ }^{1}, q_{4}, q_{5}, q_{1}{ }^{2}, q_{11}, q_{12}$. So, the credit values of index $\mathrm{q}_{3}$ andq $\mathrm{q}_{13}$ are the credit values for customers most concerned about, while the index $q_{11}$ and $q_{12}$ are the weakest indexes in terms of the credit value. Through comparing the value of $w\left(p_{i}\right)^{j}$ in Tab. 3 and the value of $v\left(p_{i}\right)^{j}$ in Tab. 4 the researchers can know, the relevance for the two group values is not high, that is because the trust degree of the customers to different indexes is different.

The threshold value for the index credit of satisfied customer demand is assumed $\beta=0.9$, thus, the credit value of each index for the supplier can be seen in Fig. 6 .

Theoretically speaking, the index $q_{4}$ and the index $q_{5}$, the index $q_{9}$ and the index $q_{10}$, the index $q_{11}$ and the index $q_{12}$, are highly relevant separately. With Fig. 6 the researchers can know, the total credit evaluation results of the three group indexes are also roughly similar separately, and through analyzing Fig. 6 the researchers can conclude the corresponding $f^{H}, f^{M}, f^{L}$ of the three group indexes are also roughly similar separately. The analysis of the credit evaluation related big data of the supplier shows that the credit evaluation data of the three group indexes are also highly correlated separately, so, with the practice the authors have validated the index $q_{4}$ and the index $q_{5}$, the index $q_{9}$ and the index $q_{10}$, the index $q_{11}$ and $q_{12}$, are highly correlated separately in terms of credit value.

\subsection{Cost Optimization Process Analysis}

Combining B2C transaction process' CWPSN model's structure, and the credit evaluation process analysis results in section "Credit Evaluation Process Analysis", providing B2C network supplier credit cost optimization investment process Petri net $(C C O I P P N)$ model structure, which is shown in Fig. 7.

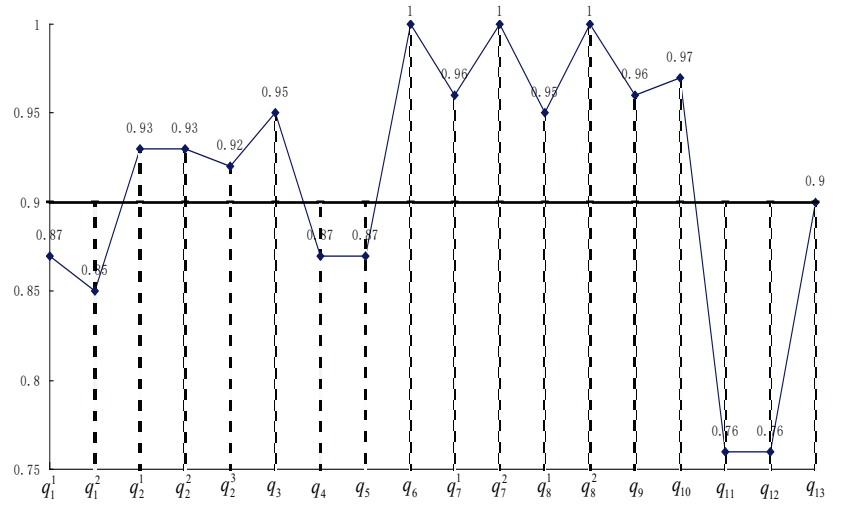

Figure 6 The supplier each index's credit value

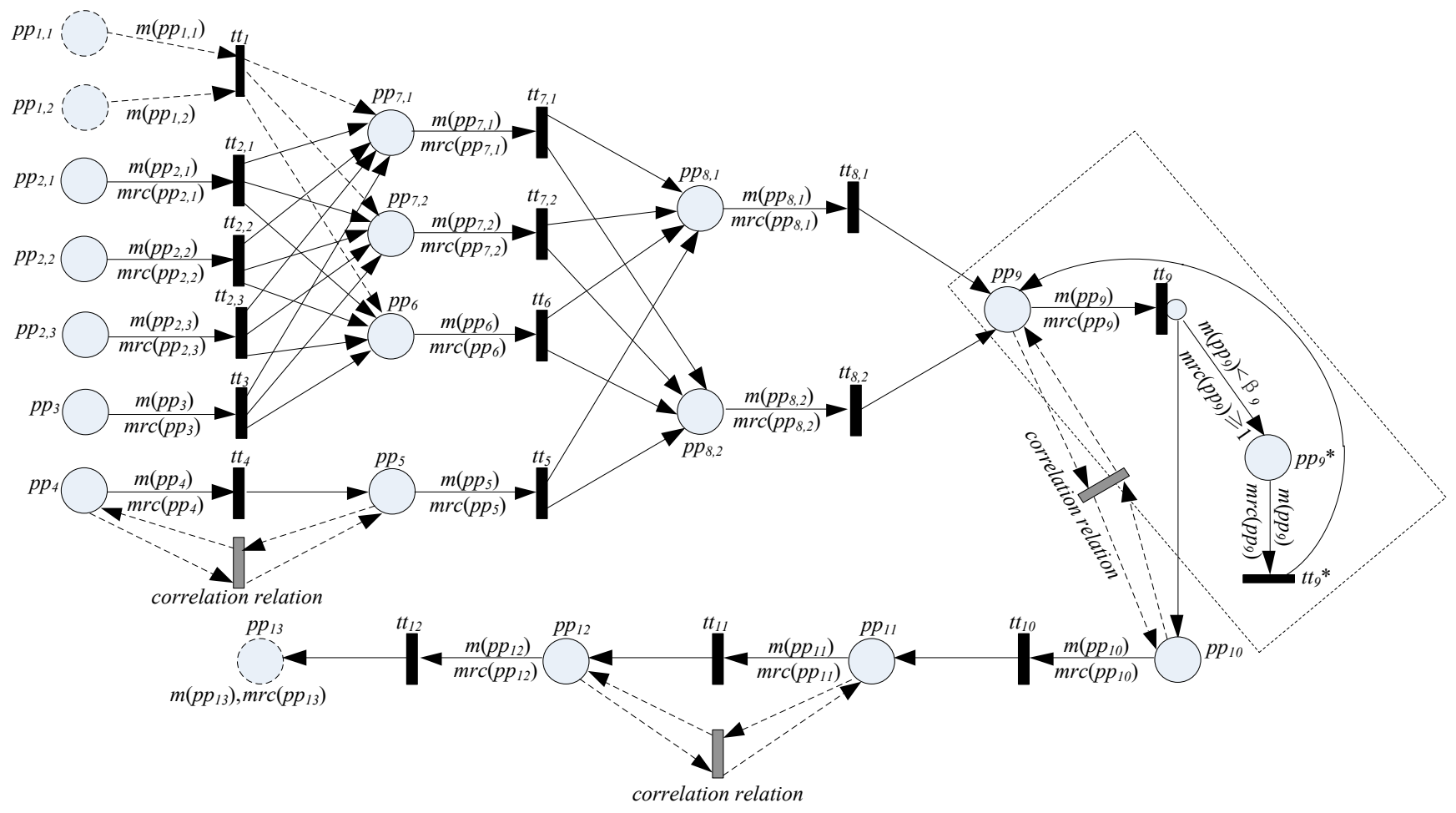

Figure 7 CCOIPPN model for B2C network supplier

Because the output of Fig. 5 is the input of Fig. 7, so the places and the places contained credit evaluation indexes in Fig. 7 also have corresponding relations to the places and the indexes in Fig. 5, that is, the implications of the place $p_{i}$ in Fig. 5 and the place $p p_{i}$ in Fig. 7 are corresponding, and they contain the same credit evaluation index $q_{l}^{j}$. The corresponding relations are shown in Tab. 5 .
In Fig. 7, the transitions as $t t_{1}, t t_{2,1}, t t_{2,2}, t t_{2,3}, t t_{3}, t t_{4}, t t_{5}$, $t t_{6}, t t_{7,1}, t t_{7,2}, t t_{8,1}, t t_{8,2}, t t_{9}, t t_{10}, t t_{11}, t t_{12}, t t_{13}$ represent the analysis to the corresponding places contained indexes' credit degree. Each place's transition trigger condition (the condition for cost optimization investment) $\beta$ value is constant as 0.9 , in this paper, for expression distinctly, the authors have not marked in Fig. 7. 
In Fig. 7, because the credit evaluation indexes contained in $p p_{1,1}, p p_{1,2}$ are the supplier's external economic surroundings indexes, the credit evaluation index contained in $p p_{13}$ is the other indexes' comprehensive reflection, so they are not in the range of cost optimization investment, and in Fig. 7 the authors marked the corresponding places and connections with dotted lines, the three places marked in Fig. 7 only for exhibiting the figure's integrity. In addition to the credit evaluation indexes contained in $p p_{1,1}, p p_{1,2}, p p_{13}$, all the other credit evaluation indexes faced with the credit cost optimization investment problem in the condition of low credit degree. For the figure expression distinctly, in Fig. 7 , the authors only make $p p_{9} \rightarrow t t_{9} \rightarrow p p_{9}{ }^{*} \rightarrow t t_{9}{ }^{*} \rightarrow p p_{9}$ as an example to illustrate the cost optimization investment process of credit evaluation index $q_{9}$ contained in $p p_{9}$, the investment optimization's transition trigger condition is credit evaluation result $m\left(p p_{9}\right)<\beta_{9}=0.9$. Whereas, $\operatorname{mrc}\left(p p_{i}\right)$ is another recessive restraint condition for transition trigger, that is, the ratio of marginal profit and marginal cost should be $m r c\left(p p_{i}\right) \geq 1$. (Here, in Fig. 7 the authors need to explain the different indexes only according to the descending order of $m r c\left(p p_{i}\right)$ to optimize the cost investment, while not according to the order of B2C transaction process. In Fig. 7, the authors mark $p p_{9}$ contained index $q_{9}$ 's cost optimization investment process only for explaining the characteristics of cost optimization investment business structure of this index.). The credit cost optimization investment processes for the other credit evaluation indexes can be understood to refer to this process. In Fig.7, the relational credit evaluation indexes corresponding places are $p p_{4}$ and $p p_{5}, p p_{9}$ and $p p_{10}, p p_{11}$ and $p p_{12}$, so, the authors mark their corresponding correlations with correlation connections (virtual connections) and correlation transitions in Fig. 7.

Table 5 Correspondence or Containing Relations among $p_{i}, p p_{i}$ and $q_{i}^{j}$

\begin{tabular}{|c|c|c|c|c|c|c|c|c|c|c|c|c|c|c|c|c|c|c|}
\hline Model or & \multicolumn{18}{|c|}{ Correspondence or Containing Relations among $p_{i}, p p_{i}$ and $q_{i}^{j}$} \\
\hline$C W P S N$ & $p_{1}$ & $p_{1}$ & $p_{2}$ & $p_{2}$ & $p_{2}$ & $p_{3}$ & $p_{4}$ & $p_{5}$ & $p_{6}$ & $p_{7}$ & $p_{7}$ & $p_{8}$ & $p_{8}$ & $p_{9}$ & $p_{10}$ & $p_{11}$ & $p_{12}$ & $p_{13}$ \\
\hline$C C O I P P N$ & $p p_{1,1}$ & $p p_{1,2}$ & $p p_{2,1}$ & $p p_{2,2}$ & $p p_{2,3}$ & $p p_{3}$ & $p p_{4}$ & $p p_{5}$ & $p p_{6}$ & $p p_{7,1}$ & $p p_{7,2}$ & $p p_{8,1}$ & $p p_{8,2}$ & $p p_{9}$ & $p p_{10}$ & $p p_{11}$ & $p p_{12}$ & $p p_{13}$ \\
\hline Indexes & $q_{1}{ }^{1}$ & $q_{1}^{2}$ & $q_{2}{ }^{1}$ & $q_{2}^{2}$ & $q_{2}{ }^{3}$ & $q_{3}$ & $q_{4}$ & $q_{5}$ & $q_{6}$ & $q_{7}^{1}$ & $q_{7}^{2}$ & $q_{8}{ }^{1}$ & $q_{8}^{2}$ & $q_{9}$ & $q_{10}$ & $q_{11}$ & $q_{12}$ & $q_{13}$ \\
\hline
\end{tabular}

Table 6 The ratio of marginal profit and marginal cost of the supplier's each index investment $(M R(q) / M C(q))$

\begin{tabular}{|c|c|c|c|c|c|c|c|c|c|}
\hline Index & $M R / M C$ & Index & $M R / M C$ & Index & $M R / M C$ & Index & $M R / M C$ & Index & $M R / M C$ \\
\hline$q_{2}{ }^{2}$ & 20.03 & $q_{3}$ & 90.02 & $q_{6}$ & 11.09 & $q_{8}{ }^{1}$ & 18.62 & $q_{10}$ & 32.03 \\
\hline$q_{2}{ }^{3}$ & 13.58 & $q_{4}$ & 10.32 & $q_{7}{ }^{1}$ & 22.03 & $q_{8}{ }^{2}$ & 29.02 & $q_{11}$ & 23.58 \\
\hline$q_{2}{ }^{3}$ & 8.62 & $q_{5}$ & 0.67 & $q_{7}{ }^{2}$ & 33.58 & $q_{9}$ & 10.32 & $q_{12}$ & 28.62 \\
\hline
\end{tabular}

Supposing the ratio of marginal profit and marginal cost for the index investment is shown in Tab. 6 (the table data only for illustrating problems, and have not practical significance).

Because the authors suppose the index credit value optimization's threshold as $\beta=0.9$, therefore, in Tab. 4 the satisfied optimization condition's indexes are $q_{1}{ }^{1}, q_{1}{ }^{2}, q_{4}$, $q_{5}, q_{11}, q_{12}$, in Tab. 6 the satisfied optimization condition's indexes are $q_{4}, q_{11}$, and $q_{12}\left(q_{1}{ }^{1}\right.$ and $q_{1}{ }^{2}$ are the external surroundings credit evaluation indexes, $q_{5}$ is the credit evaluation index that satisfied the condition of $M R(q) / M C(q)<1)$.

The supplier's each index's $M R(q) / M C(q)$ value and the satisfied optimization condition's indexes (the square frame indexes) are shown in Fig. 8.

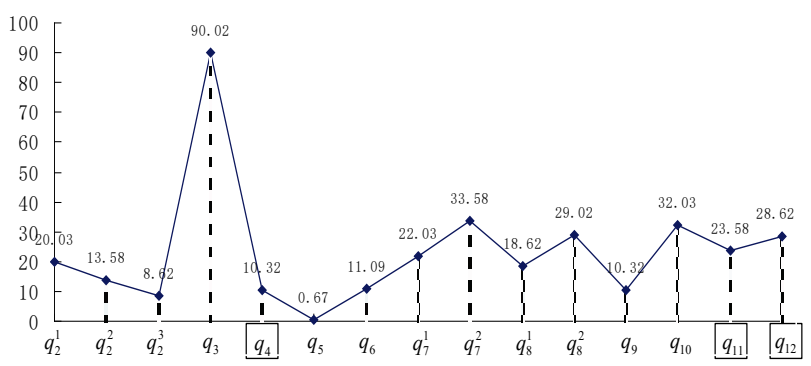

Figure 8 Each index's $M R(q) / M C(q)$ value and the satisfied optimization condition's indexes

By analyzing Fig. 8, the supplier need improve the commodity overall (reflecting in the Fig. 7, the place is $\mathrm{pp}_{4}$ ) credit degree, and the supplier return and repair commodity (reflecting in the Fig. 7 , the places are $p p_{11}, p p_{12}$ ) credit degree. With the Fig. 8 the researchers can see, the supplier should optimize the three places contained indexes' $\operatorname{MR}(q) / M C(q)$ value in the order of $q_{12}, q_{11}, q_{4}$, make the optimized indexes' credit evaluation value are greater than 0.9 or reach to a maximum feasible value that between the Fig. 6 indexes' credit evaluation value and 0.9. In addition, due to the credit evaluation results of index $q_{11}$ and $q_{12}$ are highly correlated, so in the process of investment optimization the researchers need consider synchronous implementation. Due to the investment optimization of index $q_{1}{ }^{1}$ and index $q_{1}{ }^{2}$ is very difficult to realize, and the credit degree of index $q_{13}$ is the comprehensive reflection of the other indexes' credit degree, so, in Tab. 6 and Fig. 8, the authors do not mark these indexes' $M R(q) / M C(q)$ value.

\section{CONCLUSIONS}

This paper analyzed the current deficiencies in network supplier credit evaluation. Made B2C transaction as a research case, and extended the data source of the credit evaluation for the supplier to the related big data environment. Through constructing the Petri net model as CWPSN to describe the credit value of the indexes contained in each section of the transaction process, and the importance of these indexes to the customers, for analyzing the correlations among the credit evaluation results of the indexes, and concluding the weaker credit indexes and the weaker sections in the transaction process. This paper has presented the concrete method of optimizing the credit evaluation indexes' cost investment, and described the cost optimization investment process with CCOIPPN model. This paper's research has provided methods for the credit evaluation and cost optimization of 
network supplier, and the research results can provide significant guidance for similar research.

This paper's research results will face the following difficulties in application:

(1) The confirmation of network supplier credit related big data. How to define network supplier credit related big data will directly influence the supplier credit's evaluation results. If the data source ranges are too narrow, the supplier credit situations will not be reflected fully, and if the data source ranges are too broad, on the one hand will improve the cost of data achievement and data analysis, on the other hand some lower value or incorrect data will lead to the supplier credit evaluation results deviate from the fact.

(2) Computing and analyzing the credit investment cost and profit of indexes. Due to the fact that the network supplier credit evaluation indexes exist in the whole transaction process, and the transaction data have the characteristics of dynamic and relevance, so the corresponding investment cost and profit of different indexes also have the characteristics of dynamic and relevance, these characteristics bring great difficulties for the computation and analysis of credit investment cost and profit of index.

The research methods of this paper are theoretical analysis, model construction, and case research, and in the stage of cost investment and optimization, adopted simulation setting analysis on the value of $M R(q) / M C(q)$. In future, the authors will commit themselves to the construction of application system, for ensuring the authenticity and traceability of the data for the credit evaluation; the authors will consider introducing block chain technology to the application system.

\section{Acknowledgements}

This work was supported by the National Social Science Fund of China under Grant 18BTQ083.

This paper is a revised and expanded version of a paper entitled "Credit Evaluation of Network Supplier Based on Petri Net" presented at The $7^{\text {th }}$ IEEE International Conference on Logistics, Informatics and Service Sciences, Beijing, China, 24 July 2017.

\section{REFERENCES}

[1] Hou, Y. H. (2006). Study on medium and small-sized enterprise credit evaluation indexes system in B2B marketplace of China. Soft Science, 20(4), 140-144.

[2] Feng, Y. (2011). An evaluation index system to assess business credit and enterprise under net environment. Library and Information Service, 55(8), 84-88.

[3] Fedorko, G., Molnar, V., Honus, S., Neradilova, H., \& Kampf, R. (2018). The Application of Simulation Model of a Milk Run to Identify the Occurrence of Failures. International Journal of Simulation Modelling, 17(3), 444457. https://doi.org/10.2507/IJSIMM17(3)440

[4] Zhao, P. X., Luo, W. H., \& Han, X. (2019). Time-dependent and bi-objective vehicle routing problem with time windows. Advances in Production Engineering \& Management, 14(2), 201-212. https://doi.org/10.14743/apem2019.2.322

[5] Zhao, P. X., Gao, W. Q., Han, X., \& Luo, W. H. (2019). Biobjective collaborative scheduling optimization of airport fe rry vehicle and tractor. International Journal of Simulation Modelling, 18(2), 355-365.
https://doi.org/10.2507/IJSIMM18(2)CO9

[6] Anghelache, C., Anghel, M. G., Căpusneanu, S., \& Topor, D. I. (2019).Econometric Model Used for GDP Correlation Analysis and Economic Aggregates. Economic Computation and Economic Cybernetics Studies and Research, 53(1), 183-197. https://doi.org/10.24818/18423264/53.1.19.12

[7] Agharezaei, S. \& Falamarzi, M. (2019). Particle Swarm Optimization Algorithm for the Prepack Optimization Problem. Economic Computation and Economic Cybernetics Studies and Research, 53(2). 289-307. https://doi.org/10.24818/18423264/53.2.19.17

[8] Clempner, B. J. \& Poznyak, S. A. (2018). Computing the Transfer Pricing for a Multidivisional Firm Based on Cooperative Games. Economic Computation and Economic Cybernetics Studies and Research, 52(1), 107-126. https://doi.org/10.24818/18423264/52.1.18.07

[9] Jiang, Z. B. (2004). Petri net and its application in modeling and control of manufacturing system. Beijing, China: Mechanical Industry Press, 21, 105, 118-137.

[10] Meng, X. G. \& Yan, H. S. (2012).Products demand forecasting in knowledgeable manufacturing systems based on attributes fuzzy Petri nets. Systems Engineering -Theory \& Practice, 32(4), 790-797.

[11] Simon, E., Oyekan, J., Hutabarat, W., Tiwari, A., \& Turner, C. J. (2018). Adapting Petri nets to DES: Stochastic modelling of manufacturing systems. International Journal of Simulation Modelling, 17(1), 5-17. https://doi.org/10.2507/IJSIMM17(1)403

[12] Li, Y. J., Wang, X. Q., \& Qiao, X. J. (2014). Spread model of major infectious disease based on generalized stochastic Petri nets. Chinese Journal of Management Science, 22(3), 74-80.

[13] Han, W. M., Yuan, L. L., \& Ye, T. F. (2011). Research on the lead time bullwhip effect measurement based on stochastic Petri nets. Chinese Journal of Management Science, 19(2), 116-123.

[14] Chen, J. N., Huang, Y. M., \& Chu, W. C. C. (2005). Applying dynamic fuzzy Petri net to web learning system. Interactive Learning Environments, 13(3), 159 -178. https://doi.org/10.1080/10494820500382810

[15] Zhang, L., You, X., Jiao, J. X., et al. (2009). Supply chain configuration with co-ordinated product, process and logistics decisions: an approach based on Petri nets. International Journal of Production Research, 47(23), 66816706. https://doi.org/10.1080/00207540802213427

[16] Wang, W. B. \& Da, Q. L. (2007). Remanufacturing supply chain modeling and analysis based on generalized stochastic Petri nets. Systems Engineering-Theory \& Practice, (12), 5661.

[17] Gan, Z. B., Wang, Y. F., Wei, D. W., \& Zhang, J. L. (2004). Petri net-based modeling of taxation business process in ecommerce. Journal of Changsha University of Electric Power (Natural Science), 19(4), 59-62.

[18] Li, X. M. (2014). Evaluation of project uncertainty management method based on Petri net model. Statistics and Decision, (15), 176-178.

[19] Huang, M., Lin, X., \& Hou, Z. W. (2013). Modeling method of fuzzy fault Petri nets and its application. Journal of Central South University (Natural Science), 44(1), 208-214.

[20] Wang, L., Chen, Q., Gao, Z. J., et al. (2015). Knowledge representation and general Petri net models for power grid fault diagnosis. IET Generation, Transmission and Distribution, 9(9), 866-873. https://doi.org/10.1049/iet-gtd.2014.0659

[21] Chao, D. Y. \& Wu, K. C. (2013). An integrated approach for supervisory control of a subclass of Petri nets. Transactions of the Institute of Measurement and Control, 35(2), 117-127. https://doi.org/10.1177/0142331211424428

[22] Farooq, A., Ilyas, F., Sher, A. K., et al. (2014). Petri netbased modeling and control of the multi-elevator systems. 
Neural Computing and Applications, 24(7-8), 1601-1612. https://doi.org/10.1007/s00521-013-1391-1

[23] Zhang, Z. M. \& Wu, W. M. (2011). Combined buffer preallocation and siphon control for deadlock prevention in Petri nets. International Journal of Production Research, 49(20), 6125-6154.

https://doi.org/10.1080/00207543.2010.511636

[24] Wu, Z. H. (2006). Petri net introduction. Beijing, China: Mechanical Industry Press, 181-187.

[25] Kurt, J. \& Lars, M. K. (2015). Colored Petri nets: A graphical language for formal modeling and validation of concurrent systems. Communications of the ACM, 58(6), 61-70. https://doi.org/10.1145/2663340

[26] Zhu, L. Z. \& Zhang, H. X. (2006). Modeling in electronic business workflow based on colored Petri nets. Journal of China University of Petroleum (Edition of Natural Science), 30(4), 140-147.

\section{Contact information:}

Yonggui FU, Associate Professor

Corresponding author

School of Information, Shanxi University of Finance and Economics

696 Wucheng Road, Xiaodian District, Taiyuan 030006, Shanxi Province, China

E-mail: fygzcd@163.com

Jianming ZHU, Professor

School of Information, Central University of Finance and Economics,

39 South College Road, Haidian District, Beijing 100081, China 